\title{
Research on Advertising Planning Innovation against the Background of Media Integration
}

\author{
Songjiang Liu \\ Department of Arts, Gongqing College, Nanchang University, 332020, China.
}

\begin{abstract}
Keywords: Media integration, Internet economy, background, advertising, planning, innovation, marketing model.
\end{abstract}

\begin{abstract}
The transformation of digital technology has brought about the transformation of the advertising industry and the integration of the advertising market. With the rapid development of microfilms, microfilm advertisements are also highly sought after, and a large number of highly acclaimed masterpieces have emerged and caused heated discussions. In the era of media integration, the prospect of micro-film advertising is full of opportunities, vibrant, full of thorns, and crippling crisis. We must admit that a profound advertising revolution is already imminent. Based on this, how microfilm advertisements conform to the trend of media convergence to plan, innovate and promote has become a problem that advertising communicators have to face. In this context, the media's dissemination forms tend to be diversified and fragmented, and the media content and forms of consumer contact are more extensive.
\end{abstract}

\section{Introduction}

Philip Kotler once mentioned: "Competition brings about market fragmentation, innovation brings about market integration, and the market swings between fragmentation and reintegration." His statement precisely confirms the two paradigms of market evolution. Relationships, from market segmentation to market integration as market differentiation is the market evolution paradigm in the era of industrial economy. Its concept was put forward by the American market scientist Wendel Smith in the 1950s. Due to the development of specialized division of labor and the difference in consumer demand, the same market is subdivided into sub-markets with different attributes. Each sub-market has obvious differences due to the production of different quality products and to specific consumer groups as market segmentation. After the 1990s, the development of informatization shifted us from the industrial economy to the information economy era. A series of changes have taken place in the social production methods. Market integration has evolved from several industries at the beginning to more market areas, thus becoming a market with mainstream paradigm. Market integration is not an isolated economic phenomenon. It is the "matchmaker" between technology convergence and industrial integration. Technology integration is oriented by market integration, and industrial integration is based on market integration. Since the 21st century, digital technology has represented a new generation of information technology revolution and the popularity of Internet technology, which has set off a new wave of market integration. However, how to make good use of the opportunities brought about by this market integration is an issue that needs to be answered urgently for each industry. The advertising industry as an information service industry is no exception.

Microfilm advertising is a new form of advertising that has been accompanied by the widespread dissemination of microfilms. It usually means that the playback duration is between 5 and 50 minutes. It adopts the creation, shooting, and expression techniques of the film, and has the plot and characteristics of the film. It directly or indirectly promotes certain the short video of a particular brand or product. Almost all famous micro-film works are shot by advertisers and have direct or indirect advertising purposes. It is because of this connection between micro-film advertising and micro-movie that creates a natural associated relationship between micro-film and advertising.

The purpose of advertising push and delivery is to expand brand awareness, enhance product influence and product promotion, thereby affecting consumers' consumer psychology and increasing 
the profitability of enterprises. Advertising is affected by various factors, and a series of influencing factors constitutes in the advertisement environment and advertising planning process, various environmental factors need to be comprehensively considered to improve the systematicness and flexibility of advertising planning in order to respond to ever-changing environmental changes. Today, with the enrichment of media forms, apart from the traditional political environment, economic conditions, cultural atmosphere and other influencing factors, the form of advertising communication, the content of planning, and the role of market positioning have become more prominent and the influence has become more profound. With the popularization of the Internet today, the combination of online media and media technologies has opened up a vast market space for webpage advertisements. Everyone is the recipient and potential communicator of advertisements, regardless of whether they are the media, forms or audiences of advertisements. All different from the past, the entire environmental system has changed completely. Media integration breaks the single mode of advertising communication. Under the interaction of various environmental factors, the advertising planning environment presents new features.

\section{The Proposed Methodology}

\subsection{The Key Points of Advertising Planning Innovation in Media Convergence Environment.}

The deep integration of the media has further complicated the advertising market environment. Online media platforms are springing up and bring consumers a variety of media choices, which will inevitably affect the way and effects of advertising communication. The direction of the wind and the content of innovative advertising planning can improve the effectiveness of advertising. The current advertising plan has broken through the shackles of the traditional model. It not only includes product promotion, but also has diversified market requirements covering corporate culture, lifestyle, quality pursuit, brand building, and organizational relationships, reflecting the innovativeness and universality of advertising. , guidance and value, form an integrated, systematic advertising content, enhance the appreciation and resonance. Advertising planning itself is a holistic project that closely connects with the market, the audience and the enterprise. Advertising planning covers market analysis, advertising positioning, advertising creativity and other aspects. Specific analysis is carried out in this regard $[1,2]$.

After China's accession to the WTO in 2005, the advertising market was completely open. Multinational advertising companies launched large-scale joint mergers and acquisitions with strong financial strength. This made it possible for China's market expansion to enter an era of accelerated growth. Local advertising companies were acquired or squeezed and faced huge The survival and development crisis. China's advertising industry has to face enormous challenges. Starting late and starting at a low level cannot be a permanent excuse for China's advertising industry. How to make local advertising companies bigger and stronger so that they can achieve group and scale development, thus opening up the expansion of China's advertising industry The model has become an imminent task.

In addition, with the development of digital communication technology, the popularization of new media such as mobile phones and the Internet has caused a certain amount of impact on traditional advertising services, and has also led to the transformation and upgrading of advertising models, which has created new opportunities for China's advertising industry to catch up with the super-developed countries.

Under the influence of the Internet, the number of online users has grown rapidly, attracting a large number of advertisers to shift their focus to online advertising distribution channels, forming a three-way competitive landscape between new and old media, traditional media, and emerging media. Change has occurred. Under this background, the traditional market research methods can no longer meet the needs of market changes, and cannot obtain accurate and timely market information. It is difficult to judge and analyze the direction of market demand. This requires advertisers to change their traditional ideas and innovates market research and research methods. Capture market information at the first time, gather market data for advertising planning, and design advertisements 
that meet public psychology. With the rapid development of communication technology and statistical technology, it provides more advanced support for market investigation and analysis, making accurate market research possible, but at the same time it also increases the difficulty and complexity of market research. Advertisers need to be based on actual conditions. Combine the product's life cycle and audience's target, consider the profitability and economy of advertising means at the same time, choose the optimal research method, and make different survey methods for different audience groups. For example, before advertising a young group of products, it is necessary to first fully investigate the living habits and consumption patterns of young people. Young audiences are the main users of mobile phones and networks. For this part of the group, advertising should focus on network interaction and mobile phones. In the webpage advertisement, to increase the advertisement exposure rate, reception rate and browsing rate. In addition, we can also use the Internet platform to use email questionnaires, online questionnaires, sweepstakes, and other methods to investigate the user's propensity to consume. Through the results of statistical analysis, the current needs and potential needs of consumers are studied. Occupy the market in one step [3, 4].

Industrial expansion mainly occurs in the growth phase of the industrial life cycle. This is due to the expansion of production scale, rapid growth in demand, the maturation of production technology and the diversification of stable products. It has a decisive influence on the final development scale of a particular industry and is an extremely important stage in the development of the industry.

The positioning of advertisements has an important influence on the overall value of the company. Therefore, explicit positioning and innovation of advertisements can increase the true effectiveness of advertising planning, and thus continuously strengthen the effectiveness of advertisements. In general, the success of positioning directly affects the success or failure of advertising planning and further affects the market expansion of the entire enterprise. Generally speaking, the traditional advertising positioning emphasizes a single line model. From the advertising sources, material, products, markets, consumers, and planning and execution of activities, the division of labor is clear. Every aspect needs precise grasp and relationship. Defining, in a relatively strict case, a single differentiated positioning will form a unified advertising planning and positioning. The innovative advertising plan emphasizes more on a comprehensive positioning model, which comprehensively controls the products. In general, the enterprise will conduct its own product value, market analysis, consumer customers, advertising value, etc.

\subsection{Microfilm Advertising in the Background of Media Convergence.}

The media fusion was first proposed by Prof. Pul, professor of Massachusetts Institute of Technology, and the intention was to refer to the trend of multi-functional integration of various media. With the development of modern times, this concept has been greatly expanded. It not only covers the integration of media forms, but also integrates various elements such as media functions, communication methods, ownership, and organizational structure. Especially in recent years, the rapid development of the Internet, especially the widespread use of mobile Internet and the popularization of emerging terminals such as smart phones, has accelerated the organic integration of various media resources.

Media integration is an inevitable requirement for the development of the times, and it is also a combination of multiple objective factors. As an industry that survives and develops by relying on information, advertising is extremely sensitive to changes in the media environment. New changes in the media environment will inevitably drive changes in the format of advertising. Although micro-film advertising can't be said to be the most suitable form of advertising under the new media environment, it has unique development advantages and will give the overall advertising industry a

Strong driving force and new growth point.

Since the birth of micro-film advertisements to date, it has only been a short period of several years. Theoretical research obviously lags behind the practical application of the industry, and it is inevitable that there are many problems that restrict the pace of its development.

Micro-film advertising belongs to online advertising in a sense, and online advertising is different from traditional advertising. It is very suitable for small-scale ethnic groups to actively seek information. Microfilm advertising is to provide differentiated services for different audience groups 
based on the characteristics of minority distribution, and also to accurately deliver these services to them, which traditional media cannot achieve. Therefore, we must make full use of the digital advantages of media convergence, pay attention to "point-to-point" communication, select suitable carriers for different audiences, and push, broadcast, direct, fixed, and fixed-point to the most appropriate time. Ways to communicate to the most demanding audience and achieve accurate communication.

\subsection{Marketing Convergence Model of Advertising Industry.}

At present, the advertising industry is undergoing market integration, and more and more experts in the industry and academia are paying attention to the changes and future trends of the advertising industry in the context of market integration. However, most of them are based on descriptions of phenomena and forecasts of the future. How does the market integration of the real advertising industry happen? How to reveal the evolution process of the integration of the advertising industry market from inside is worth exploring.

\section{Conclusion}

Media integration is the inevitable outcome of the mass media era. Under this background, the market puts forward higher requirements for advertising planning. The traditional advertising communication mode cannot adapt to the current market environment, and effectively uses multimedia technology and network technology to cater to consumer psychology. In order to achieve advertising innovation, we can use the influence and advocacy of advertising to improve the effectiveness of advertising. At present, advertising planning has not yet been fundamentally innovative, and there are still imperfections, but innovative development is still the mainstream of its progress. With the advent of the digital age, new industrial forces such as mobile application development agencies, brand interactive marketing agencies, digital integrated marketing agencies, and e-commerce service providers have appeared. Therefore, the advertising industry chain must not only link up with the industry links between upstream and downstream specialized enterprises and institutions in the advertising industry, but also be intertwined with the industrial chain of other industries and jointly extend and expand the advertising industry chain.

\section{Acknowledgements}

The Project is supported by a Youth grant from Jiangxi Provincial Social Science Foundation of China during the 12th Five-Year Plan Period (Grant No. 13WX23), A Study on Mass Cultural Narrative and its Guiding Mechanism in the New Media Context;

A science project from Education Department Jiangxi province (Grant No.171466), Research on optimal management of agricultural products cold chain logistics under the technology of Internet of things.

\section{References}

[1]. Igbinovia, M.O., Ambrose, S.E. and Solanke, E.O., 2018. Library and Social Media use as Predictors of National Integration among Distance Learning Students in Benin Study Center, Nigeria International Information \& Library Review, pp.1-14.

[2]. Chen, Q., Zhang, G., Yang, X., Li, S., Li, Y. and Wang, H.H., 2017. Single image shadow detection and removal based on feature fusion and multiple dictionary learning. Multimedia Tools and Applications, pp.1-24.

[3]. Barbero, E.J., Vetere, F., Madeo, A. and Zinno, R., 2017. Analytic integration of singular kernels for boundary element analysis of plane orthotropic media. Composites Part B: Engineering, 108, pp.393-412. 
[4]. Press, M.J., Howe, R., Schoenbaum, M., Cavanaugh, S., Marshall, A., Baldwin, L. and Conway, P.H., 2017. Medicare payment for behavioral health integration. New England Journal of Medicine, 376(5), pp.405-407. 